\title{
Subjetivação e pertencimento: a inefetividade da preservação ambiental como fato gerador do dano existencial
}

\author{
Subjectivation and belonging: the ineffectiveness of environmental preservation \\ as a reason for existential damage
}

\author{
Simone Murta Cardoso do Nascimento* \\ Elcio Nacur Rezende*
}

\section{Resumo}

\begin{abstract}
A proteção ambiental comporta diversos vieses, inclusive por meio transverso do reconhecimento, valorização e proteção das comunidades tradicionais que, em razão das características próprias de subjetivação e construção identitária, mantém estreito vínculo com o território e a natureza. O estudo do processo subjetivo de construção de identidades pessoais e da cultura grupal demonstra que em relação às comunidades tradicionais a subjetivação se dá a partir de estreita relação com o meio ambiente e a proteção dessas comunidades, dentre as quais se encontram as indígenas, configurando maneira complementar de proteção das características ambientais naturais. Políticas governamentais, então, devem englobar ações de defesa e, sobretudo, abstenções e ingerências na cultura dos povos indígenas. Violações no modo de ser e de viver das comunidades tradicionais podem configurar o chamado dano existencial, levando ao dever de reparação. Assim, o presente estudo tem como objetivo a análise da construção da subjetividade dos grupos indígenas como fator de tutela do meio ambiente, sendo desenvolvido através do método dedutivo, com ênfase na pesquisa exploratória ancorada em levantamento bibliográfico. Conclui-se que o reconhecimento e a defesa da cultura indígena, aliada à proteção dos territórios originalmente ocupados, promovem a manutenção das características ambientais.
\end{abstract}

Palavras-chave: Comunidades tradicionais; subjetivação; construção de identidade; preservação ambiental; dano existencial.

\section{Abstract}

\begin{abstract}
Environmental protection involves several biases, including through the transversal recognition, appreciation, and protection of traditional communities that, due to their characteristics of subjectivity and identity construction, maintain a close link with the territory and nature. The study of the subjective construction process of personal identities and group culture demonstrates that concerning traditional communities, subjectivation occurs from a close relationship with the environment and the protection of these communities, among which are the indigenous ones, configure complementary ways of protecting natural environmental characteristics. Government policies, then, should encompass defense actions and, above all, abstentions and interference in the culture of indigenous peoples. Violations in the way of being and living in traditional communities can configure the so-called existential damage that can lead to the duty of reparation. The study aims to analyze the construction of the subjectivity of indigenous groups as a factor in protecting the environment, being developed through the deductive method, emphasizing the exploratory research anchored in a bibliographic survey. It is concluded that the recognition and defense of indigenous culture, combined with the protection of the formerly occupied territories, promotes the maintenance of environmental characteristics.
\end{abstract}

Keywords: Traditional communities; subjectivation; construction of identity; environmental preservation; existential damage.

\section{Introdução}

A tutela do meio ambiente é premente e inconteste. Tem-se como certo, atualmente que medidas devem ser empreendidas para que a devastação ambiental seja contida por razões que transcendem o aqui e agora. Impactos ambientais tornam a qualidade de vida da geração presente prejudicada e ameaçam a das futuras gerações. A par disto, a preservação ambiental garante a existência de grupos que mantêm íntima relação com o ambiente natural, preservando-o. em Direito Civil e Processual Civil; Graduada em Direito pela ESDHC e em Psicologia pela PUC Minas; Professora Universitária; Advogada. E-mail: simonemurta@hotmail.com 
Muitas são as possibilidades de intervenção para fins de proteção do meio ambiente, dependentes, via de regra, de interesses políticos e econômicos. Intervenções diretas do Poder Público para coibir práticas degradantes, punição para infratores e programas educacionais e de conscientização são algumas das vias protetivas ordinárias. Mas outras medidas também são possíveis, como a regularização do acesso e da exploração de recursos biológicos.

O presente trabalho objetiva analisar a proteção ambiental pelo viés do reconhecimento e garantia dos direitos das comunidades tradicionais, especialmente as indígenas, que têm como inerentes a sua existência a utilização respeitosa dos recursos naturais, visto a observação das práticas de coleta e modo de viver integrados com os ciclos da natureza. A inefetividade estatal para a proteção ambiental coloca em risco a existência das comunidades tradicionais; e como as políticas não reconhecem e não valorizam tais culturas ancestrais, o resultado pode afetar seu modo de vida, ou seja, em tese, pode acarretar o chamado dano existencial.

A pertinência da discussão não apenas transcende a defesa dos direitos dos indígenas, mas enfatiza o reconhecimento da importância da manutenção das culturas e preservação das comunidades como fatores de preservação ambiental. Sob a ótica própria das comunidades tradicionais, alterações no modo de viver e conviver enquadram-se no conceito, ainda pouco explorado, de dano à própria existência.

A partir disso, o presente estudo se ancora na triste realidade observada de degradação ambiental na Amazônia brasileira, onde interesses políticos e econômicos incentivam queimadas e apropriações de recursos e espaços, além de ter a política nacional como base e a desqualificação da cultura indígena a partir da imposição hegemônica do modo de viver do homem branco.

Assim, justifica-se este estudo na medida em que se pretende argumentar que o reconhecimento e a preservação da cultura dos povos tradicionais amazônicos, respeitando-lhes o território ocupado, podem contribuir para a preservação ambiental visto que, historicamente, o modo de viver das comunidades tradicionais é integrado ao meio, com a retirada apenas de recursos necessários à sobrevivência e com respeito aos ciclos naturais de crescimento e colheita.

Para a inspeção do problema e defesa do ponto de vista, traçar-se-á uma análise dos aspectos subjetivos de formação da individualidade do ser humano que, respeitadas as características étnicas, apresenta como padrão a interação com o grupo social. Abordar-se-á o conceito de comunidades tradicionais das quais as comunidades indígenas fazem parte, enfatizando-se a construção da identidade grupal e individual que se dá em íntima relação com o meio ambiente. Em seguida será abordado o conceito de dano existencial para, ao fim, aventar a possibilidade de enquadramento neste tipo de dano quando observadas alterações no modo de vida das comunidades tradicionais.

O trabalho se desenvolverá a partir de pesquisa exploratória, por levantamento bibliográfico, sob o escopo do método de raciocínio dedutivo, tomando como base conceitos da psicologia e da teoria psicanalítica.

\section{Subjetivação e configuração}

O homem se configura, inexoravelmente, a partir do outro. É na relação com o outro, membros da família, inicialmente, e do grupo social, posteriormente, que o ser biológico avança para o ser cultural apto e capaz de se desenvolver e participar dos agrupamentos humanos. É através da linguagem, que pressupõe interação com o outro, que a subjetividade é criada, que a cultura de determinado povo é repassada e a identidade grupal é reforçada. Portanto, é plenamente cabível a afirmativa de que sem o "outro" não existe o "eu".

O termo subjetivação refere-se ao movimento de tornar-se sujeito, da construção de identidade e determinação da posição na sociedade. A construção de si é a conjugação de processos psíquicos com o movimento de socialização; pode-se afirmar, portanto, que é através da interação social que o homem é despertado e moldado. Dessa forma, entende-se por subjetivação um processo de construção (DELEUZE, 1992), cujo resultado configura a subjetividade que, por sua vez, compreende tanto a dimensão individual quanto a social (CASSIANO; FURLAN, 2013).

Cabe destacar que embora vistos como termos intercambiáveis, identidade e subjetividade são conceitos distintos. Identidade é o conjunto particular de traços, crenças e sentimentos de pertencimento que configura a personalidade de alguém e o modo de ser em sociedade. Subjetividade pressupõe a autoconsciência sobre a identidade (HALL, 2004).

Traços culturais, aspectos linguísticos e organizações sociais são desenvolvidos com características peculiares a cada agrupamento social e tais aspectos passam a incorporar a identidade de cada membro daquela sociedade. Portanto, o indivíduo se individualiza como membro ao mesmo tempo em que figura como reprodutor da identidade grupal. Indivíduo e grupo, então, são estruturas autor referenciadas. 
Trazendo conceitos da teoria psicanalítica, a inserção do homem na cultura e a configuração da subjetividade se dão a partir da relação com as outras pessoas, consubstanciando o conceito do "pequeno outro" desenvolvido por Lacan (1988). A subjetividade se constrói sempre mediada pela fala, a partir da relação intersubjetiva, e com a inserção no campo simbólico, no campo compartilhado de significantes. O registro na cadeia de significantes configura o inconsciente que é locus de registro dos traços culturais e das ideologias de determinada sociedade, e conforma a sujeição do indivíduo a valores e normas. Na teoria lacaniana, o grande "Outro" se refere ao complexo de significantes culturalmente compartilhados e que passa a fazer parte da subjetividade humana ("REZENDE, NASCIMENTO, 2018, p. 347-360).

Os papéis sociais são assimilados e reproduzidos também a partir de mecanismos que têm como referência os demais membros do grupo. Funções e posições grupais partem da organização social que serão introjetadas como parcela da personalidade individual, que são agregadas às habilidades, desejos e interesses individuais. Há sociedades com maior ou menor flexibilidade para os papéis sociais, assim como há sociedades com maior ou menor aceitabilidade da diversidade. Assim, cada indivíduo se estrutura, também, a partir do papel que desempenha no grupo.

Peculiaridades surgem a partir da análise das comunidades indígenas, visto que está se dá de forma hegemônica, a partir do ponto de vista do homem branco, dominador, tendo havido, por vezes, porém hoje superado, questionamentos até mesmo sobre a configuração ou não de um agrupamento indígena como sociedade.

Cabe destacar que povos indígenas são aqueles que, tendo uma continuidade histórica com o período préinvasão colonial, são sociedades que se desenvolveram em seus territórios e se consideram distintas de outros setores das sociedades que hoje prevalecem nesses territórios ou em partes deles. Formam atualmente setores não dominantes da sociedade e estão determinados a preservar, desenvolver e transmitir às gerações futuras seus territórios ancestrais e sua identidade étnica, pensando sua existência continuada enquanto povos, de acordo com seus próprios padrões culturais, sociais instituições e sistemas jurídicos (JACOB; CHENG; PORTER, 2015, p. 40).

A imposição de concepções e valores é uma decorrência do Estado moderno que busca unificar a humanidade ao impor uma mesma religião, a cristã, mesmo padrão cultural e uma educação homogeneizada a todos os povos encontrados no território artificialmente instituído. Trata-se de um aspecto do nacionalismo que visa o exercício de um poder centralizado sobre todas as coletividades e o faz através da supressão de línguas, tradições e culturas "minoritárias", sob o argumento da construção de uma unidade nacional, mas que, em verdade, representa um projeto de dominação articulado por uma elite europeia. Surge, então, o ideal de sociedade unificada como uma artificialidade garantidora da propriedade privada burguesa (SILVEIRA, 2009).

A posição hegemônica tende a levar à concepção de que comunidades tradicionais, por terem adotado por longo período o extrativismo, a caça e a pesca como forma de subsistência, constituem realidades atrasadas e não desenvolvidas. Tal concepção parte da premissa de que progresso tecnológico e acúmulo de capital representam o ideal de sociedade desenvolvida que deve, a todo custo, ser perseguido. Assim, tende-se a impor padrões e práticas capitalistas, as sujeitando pessoas e comunidades com séculos de organização e estruturação ancestral, pois se compreende que reconhecer e aceitar a diferença pode ameaçar certezas e valores ocidentais hegemônicos..

O paradigma científico, reflexo do pensamento ocidental, não reconhece conhecimentos populares, tradicionais, nem mesmo normas de estruturação interna, de forma que as narrativas dos povos originários são consideradas subalternos (KAHMANN; BERTOLDI; FIGUEROA; BRINGUENTE, 2020).

O pensamento ocidental hegemônico se estruturou a partir do dualismo entre meio ambiente e cultura, entre natureza e o homem. Comunidades indígenas, chamados por vezes de povos da natureza, reconhecem desde sempre o que hoje se apresenta como ponto de discussão: o reconhecimento da existência de um sistema irredutível entre o ser humano e o meio ambiente, no qual um faz parte do outro. Desta forma, a perda de biodiversidade também representa a perda para a sociodiversidade, que impacta a cultura e a espiritualidade desses povos, cujas repercussões se podem verificar em todos os aspectos da cultura. Pode-se dizer, então, que transformações ambientais nas paisagens e no uso dos recursos naturais, em regra, implicam em ressignificações na relação comunidade-natureza (GUIMARÃES, 2018).

Há que se considerar que muitas crenças espirituais indígenas envolvem seres não humanos sencientes - capazes de sentir ou perceber através dos sentidos - que estão ligados a determinados espaços geográficos ou outros tipos de ligações a espaços específicos que envolvem o cuidar responsável. Tais seres sencientes não humanos são frequentemente conceituados como parte de uma teia de relações nas quais os humanos também participam. Assim, para muitas culturas indígenas, os humanos têm responsabilidades para com o mundo ao seu 
redor que requerem cuidado nas ações que realizam e uma necessidade de considerar os interesses dos animais e outros tipos de seres. Assim, compreende-se que para esses povos, as espiritualidades, identidades, idiomas e sistemas de governo indígenas vêm da terra. O sustento da sabedoria, cosmo visões, filosofias e valores vêm da terra. A fonte do conhecimento vem da terra e do mundo espiritual que ela abrange (HENDRIX, 2008, p. 178).

Nas comunidades tradicionais, é primordialmente por imposição externa que a cultura se altera, visto que a tradição mantém costumes e valores. Sob o nefasto argumento de melhoria da qualidade de vida se perde conhecimento, práticas são substituídas, conceitos e concepções são impostos. Premente, portanto, a existência de normas protetivas efetivas da cultura dos povos tradicionais, bem como de reconhecimento quanto sua pertença ao meio e o respeito à natureza.

Deve-se atentar, contudo, que apenas a consolidação de dispositivos constitucionais que amparem tais culturas tradicionais não significa efetividade e, muito menos que os direitos protetivos das comunidades indígenas "estejam resguardados do processo hegemônico civilizatório do sistema-mundo europeu ou euro-estadunidense, capitalista/patriarcal, moderno/colonial" (KAHMANN; BERTOLDI; FIGUEROA; BRINGUENTE, 2020, p. 80). Há que se empreender medidas de reconhecimento e valorização das culturas tradicionais com a subsequente proteção.

\section{Meio ambiente como formador da identidade dos povos tradicionais}

Inconteste, portanto, a configuração das comunidades tradicionais, como as indígenas, se dá a partir e em função do meio onde vivem. É na interdependência com o ambiente que os cercam que os membros da comunidade se organizam e, a partir daí, passam a se configurar. Práticas, hábitos e papéis sociais são, portanto, adquiridos e transmitidos a partir dos recursos disponíveis, assim como ferramentas e utensílios criados para bem lidar com as adversidades do ambiente. A cultura, portanto, está entrelaçada ao meio e a preservação ambiental é inerente à existência.

O Decreto $n^{\circ}$ 6.040, de 07 de fevereiro de 2007, que institui a Política Nacional de Desenvolvimento dos Povos e Comunidades Tradicionais, traz o conceito legal de comunidade tradicional. Segundo esse documento, povos e comunidades tradicionais são os "grupos culturalmente diferenciados e que se reconhecem como tais, que possuem formas próprias de organização social, que ocupam e usam territórios e recursos naturais como condição para sua reprodução cultural, social, religiosa, ancestral e econômica, utilizando conhecimentos, inovações e práticas gerados e transmitidos pela tradição". Acresce a informação de que são territórios tradicionais "os espaços necessários a reprodução cultural, social e econômica dos povos e comunidades tradicionais, sejam eles utilizados de forma permanente ou temporária" (BRASIL, 2007).

São consideradas comunidades tradicionais, reconhecidas pela lei, aquelas que possuem um modo de vida estreitamente relacionado com o local onde vivem e com os recursos naturais de que dispõem, os quais têm mais que um valor de uso, mas também possuem valor simbólico e espiritual, permeando as representações indenitárias de tais grupos (SANTILLI, 2004).

As comunidades tradicionais, mais comumente relacionadas, são os povos indígenas e as remanescentes de quilombos, mas respeitando sempre o direito de todas as comunidades que mantenham vínculo econômico, social e cultural, de maneira duradoura e de interdependência com o meio onde vivem (SANTILLI, 2004).

A relação dos membros das comunidades tradicionais com o meio é de respeito e de reconhecimento da interdependência. Ou seja, o conhecimento repassado ao longo das gerações define usos e limites de exploração, não existindo a concepção de acumulação e produção de capital. Assim, retira-se do ambiente o necessário para a vida, respeitando-se fluxos de recomposição.

As comunidades tradicionais são reconhecidas como detentoras de conhecimento tradicional, repassado verbalmente de geração a geração, e que decorre de estreito vínculo com o meio onde vivem, não sendo possível uma distinção entre meio, comunidade e cultura (FERES; MOREIRA, 2014). Assim,

Pela denominação "conhecimentos tradicionais" entende-se as informações e as práticas de comunidades (indígenas, quilombolas, ribeirinhas, ou outras que vivem em estreita relação com o ambiente), que possam se transformar em valor, associadas ao patrimônio genético. É, por exemplo, o conhecimento acerca das potencialidades curativas de determinada planta que é transmitido oralmente entre as gerações. (BOFF, 2015, p. 112) 
O conhecimento tradicional decorre de processos de adaptabilidade ao meio, os quais produziram ações e relações de simbiose com a natureza e seus elementos, possibilitando a vivência social e cultural, nas trocas de saberes, usos e recursos como materialização do modo de integração e transformação mútua entre os seres humanos e a natureza (DANTAS, 2008).

Ao se considerar a cultura dos povos tradicionais, posse e propriedade, por exemplo, são concepções impostas, visto que para as comunidades tradicionais a terra não pertence a pessoas e grupos, é de todos e de ninguém, muitas vezes relacionadas a divindades. A relevância de tais conceitos - posse e propriedade- só se faz presente quando a definição de titularidade se configura a favor das comunidades e com vistas a tutelar seus interesses contra ameaças e violações externas, em regra, oriundas das ações do homem branco dominador. A relação das comunidades tradicionais com as terras que ocupam não é de domínio, mas de pertencimento. $O$ homem pertence ao meio e este o configura.

Como se pode perceber, a própria definição de comunidade tradicional destaca a relação com o meio e, por não compactuarem à noção capitalista de exploração dos recursos ambientais, vivem integrados e em posição de respeito à natureza.

\section{Direitos e deveres preservacionistas}

A afirmativa de que todos têm direito ao meio ambiente ecologicamente equilibrado, devendo ser considerado bem de uso comum do povo e reconhecido como essencial à sadia qualidade de vida, acrescida à disposição do Poder Público, assim como a coletividade, a obrigatoriedade de preservação para atendimento dos interesses da atual geração e das futuras (BRASIL, 1988) faz da preservação ambiental direito fundamental.

Vez que reconhecido como fundamental, o direito ao meio ambiente ecologicamente equilibrado, por si, requer análise. Além do escopo meramente formal de inserção de tal direito na Constituição da República, aspectos de ordem sociológica, política e histórica devem ser contemplados quando há da definição de sua jusfundamentalidade, como trazem Sampaio e Rezende (2020).

Ancoradas em leituras inovadoras, tem-se que a dimensão sociológica decorre de circunstâncias históricas e a política é resultado de lutas e conflitos que efetivaram a revelação do direito ao meio ambiente ecologicamente equilibrado como algo fundamental (SAMPAIO; REZENDE, 2020), afirmação que se pretende aqui desenvolver. Ademais, a transindividualidade e a transgeracionalidade, pertinente a tal direito, que o coloca em posição peculiar que possibilita releituras abrangentes, ampliando não só o reconhecimento de vítimas reais e potenciais, quanto da titularidade para ações de efetivação do direito e, ainda, os mecanismos possíveis de efetivação. Ainda que de forma transversa, se faz premente à proteção ambiental, visto os inúmeros e reconhecidos impactos não só em relação aos aspectos ambientais, mas também na saúde e na própria existência da humanidade.

É preciso considerar a proteção dos direitos das minorias, aqui com foco nas comunidades tradicionais indígenas, buscando soluções que não os "amesquinhem" ou coloquem em risco sua forma de viver e sua cultura. Amesquinhar, segundo Sampaio e Rezende (2020), é deixar de atribuir o devido respeito e consideração aos direitos das minorias.

Entende-se, contudo, que se deve ir além. Exigindo-se isonomia aos atos legislativos, e que se tenha igual interesse na defesa dos direitos de outrem, tanto quanto se fosse de si próprio. Defende-se que a tutela do direito fundamental ao meio ambiente ecologicamente equilibrado deve ser feita sempre sob a ótica da humanidade, com reconhecimento das peculiaridades de participação de cada parcela da comunidade humana. É direito da humanidade a qualidade ambiental, assim como conhecer e conviver com grupos e etnias diversas.

A fundamentalidade da proteção ambiental, contudo, tem sido esvaziada, embora exaustivamente reprisada nos mais diversos contextos, seja por inexistência ou inefetividade das ações do Poder Público, muito mais voltadas aos interesses políticos e econômicos particulares do que condizente com preservação ambiental.

O que se observa é a falta de investimento em ações de preservação ambiental aliada a uma desqualificação e desconsideração da cultura das comunidades indígenas. Desta feita, ao não reconhecer, preservar e valorizar a cultura das comunidades tradicionais promove-se a extinção deforma milenar de uso adequado de recursos naturais.

Sobre este viés, a preservação ambiental dar-se-ia a partir de uma abstenção do Poder Público de ingerência sobre o modo de vida das comunidades tradicionais, que não demandam nem necessitam de medidas de educação ambiental. Lado outro, se faz necessária a efetivação da proteção destes grupos contra ingerências e ameaças externas. 
Lamentavelmente o que se observa é uma desqualificação da cultura das comunidades indígenas, com a imposição de adaptação ao modo de viver do "homem branco". Por conseguinte, o ser e existir dessas comunidades são alterados e aliados à alteração do ambiente, modificando o modo de vida, o que provoca dano de natureza existencial.

\section{Existência modificada}

O dano existencial, conceito em construção no sistema jurídico brasileiro, é espécie do dano extrapatrimonial e diz respeito às situações danosas que acarretam à vítima, ou às vítimas, impossibilidade ou grave dificuldade de executar ou dar prosseguimento a seu projeto de vida e, noutra vertente, a dificuldade de retomar sua vida de relação, nos mais diversos segmentos. Para que seja caracterizado, há de se fazer presente o nexo causal ou etiológico entre o evento danoso e o considerável impedimento ao projeto de vida ou à vida em relação da vítima (FROTA, 2013).

Trata-se de uma afetação negativa e juridicamente relevante no cotidiano da pessoa, que estabelecia determinada rotina, e, em razão de uma conduta lesiva injusta, sofreu alteração prejudicial. Tal mudança pode ser total ou parcial, permanente ou temporária, seja em uma atividade, seja em um conjunto de atividades usualmente praticadas pela vítima do dano, visto estivesse incorporado ao seu cotidiano e que precisou suprimir, modificar, delegar a sua realização. Até mesmo a necessidade de realização de modo diverso do usual pode configurar a existência do dano. O dano existencial representa, pois, uma renúncia involuntária à situação de normalidade tida em momento anterior ao dano (SOARES, 2012).

A ocorrência do dano existencial se dá em um determinado momento da vida da vítima, mas se postergará por toda sua existência, seja através da alteração na configuração do seu projeto de vida, na mudança de suas relações com seus familiares, ou em relação ao seu trabalho e nas suas relações sociais externas (BUARQUE, 2017).

O dano existencial configura, portanto, uma lesão que atinge não a integridade física ou moral do indivíduo, mas a própria existência da pessoa lesada, a forma como ela lidava com o cotidiano e com as pessoas de seu relacionamento. São danos de natureza existencial, que atingem o homem enquanto essência, no seu interagir com o ambiente (BUARQUE, 2017).

O dano existencial é, então, objetivamente verificável pela perda da capacidade ou alteração significativa de realização de atos simples às pessoas com plena capacidade (SOARES, 2012) em decorrência de ato injusto de outrem. O impacto altera como a vítima se posicionava no mundo e nas relações que estabelecia.

Há que se destacar que, sendo alteração efêmera ou não revestida de relevância jurídica, não se está diante de um dano existencial propriamente dito. Deve-se verificar significativo impacto na vida da vítima capaz de justificar a intervenção Estatal que, através da prestação jurisdicional, irá impor medida reparatória ao causador do dano.

O dano existencial subsiste como espécie de dano imaterial, independente das outras espécies de danos extrapatrimoniais, podendo ser com eles cumulados sob permissão do princípio da reparação integral. Pode ser um dano individual ou coletivo; pode decorrer de conduta relativa à responsabilidade objetiva ou subjetiva, de fonte contratual ou extracontratual (SOARES, 2012).

Em decorrência do dano existencial surge a impossibilidade da pessoa lesada de continuar a exercer suas atividades, como habitualmente as praticava, para o regular desenvolvimento do seu projeto de vida. O momento em que o dano ocorre é delimitado, mas suas consequências se protrairão por um longo período ou até mesmo por toda a vida da vítima (BUARQUE, 2017).

Cabe destacar que no caso de danos dessa natureza devem-se intentar resultados outros que não a tradicional e questionável compensação pecuniária. Eventual condenação por dano existencial deve privilegiar a restauração, na medida do possível, da situação anteriormente vivenciada.

Considerando a direta relação das comunidades tradicionais com o meio ambiente e da construção da subjetividade individual, a partir da relação grupal daí estabelecida, supressão ou mesmo alteração das condições ambientais originais, impede-se ou, ao menos, dificulta-se a efetivação do projeto de vida individual e grupal. A imposição de concepção de vida diversa é tida como violação da dignidade e da própria configuração pessoal e grupal, representando, assim, um impacto indevido no projeto de vida.

Aqueles indivíduos que receberam cultura milenarmente construída e tinham a expectativa de transmitir o modo de vida ancestral às novas gerações, passam a ser vítimas de ações ou omissões, alterando assim seu 
projeto de vida. Uma vez identificado o liame com uma conduta, ou omissão, estariam configurados os requisitos do dano existencial.

Cabe considerar, brevemente, que o dano oriundo de omissão requer um dever preexistente de ação. É o caso em tela, visto que é atribuído ao Poder Público o dever de preservar o ambiente e respeitar a cultura das comunidades tradicionais.

\section{Considerações finais}

A proteção ambiental, dada as características próprias do bem a ser tutelado - o meio ambiente, que abarca as concepções de transindividualidade e a transgeracionalidade -, justifica o emprego de diversas concepções protetivas, inclusive através da proteção de grupos específicos como as comunidades indígenas da Amazônia.

Direito fundamental ao meio ambiente ecologicamente equilibrado é direito de todos e pressupõe respeito às comunidades tradicionais, estas devendo ser encaradas como mecanismo de preservação ambiental. Não se trata, no entanto, de impingir uma visão instrumentalista às comunidades tradicionais; é, na verdade, o reconhecimento da importância das práticas exercidas em consonância com o meio ambiente.

A configuração própria das comunidades, assim como a formação das subjetividades dos membros, ocorre a partir e em função da estreita relação que mantém com o ambiente, este não como uma fonte de recursos, mas como componente da existência compartilhada.

A imposição da visão hegemônica coloca em risco um modo de vida integrado com o meio ambiente que, via transversa, promove a preservação ambiental ancorada no respeito e na contenção da exploração.

Violações indevidas na cultura das comunidades tradicionais, sejam por ingerências externas, seja por omissão no dever de protegê-las, podem configurar dano existencial, especialmente na intromissão e alteração do projeto de vida.

A preservação do modo de vida das comunidades tradicionais transcende interesses destas; e deve configurar, por si, afã - empenho- da humanidade, seja pelo viés da preservação ambiental, seja pelo interesse comum no reconhecimento da história e da evolução do homem como ser social.

Atenta-se, então, que o estudo alcançou seus objetivos na medida em que possibilitou a demonstração da factibilidade e da pertinência da proteção ambiental pelo viés do reconhecimento e proteção das comunidades tradicionais, com atenção especial voltada para os povos indígenas, cuja estruturação individual e grupal se dá a partir de íntima relação com o meio onde vivem. Ademais, demonstrou-se a aplicabilidade do chamado dano existencial quando a forma de viver de tais comunidades é alterada de forma prejudicial.

\section{Referências}

BOFF, Salete Oro. Acesso aos conhecimentos tradicionais: repartição de benefícios pelo "novo" marco regulatório. Revista Direito Ambiental e Sociedade, Caxias do Sul, v. 5, n. 2, p. 110-127, 2015. Disponível em: http://www.ucs.br/etc/revistas/index.php/direitoambiental/article/view/3951. Acesso em: 31 out. 2016.

BRASIL. [Constituição (1988)]. Constituição da República Federativa do Brasil de 1988. Brasília, DF: Presidência da República, [2020]. Disponível em: http://www.planalto.gov.br/ccivil_03/constituicao/constituicao. htm. Acesso em: 07 out. 2020.

BRASIL. Decreto $n^{\circ}$ 6.040, de 07 de fevereiro de 2007. Institui a Política Nacional de Desenvolvimento Sustentável dos Povos e Comunidades Tradicionais. Brasília, DF: Presidência da República, [2020]. Disponível em: http://www.planalto.gov.br/ccivil_03/_ato2007-2010/2007/decreto/d6040.htm. Acesso em: 10 set. 2020.

BUARQUE, Elaine Cristina de Moraes. Dano existencial: para além do dano moral. 2017. Tese (Doutorado em Direito) - Faculdade de Direito do Recife, Universidade Federal de Pernambuco, Recife, 2017. Disponível em: https://attena.ufpe.br/handle/123456789/27899. Acesso em: 17 jun. 2020.

CASSIANO, M.; FURLAN, R. O processo de subjetivação segundo a esquizoanálise. Psicologia \& Sociedade, São Paulo, v. 25, n. 2, p. 372-378, 2013. Disponível em: https://www.scielo.br/pdf/psoc/v25n2/14.pdf. Acesso em: 23 out. 2020. 
DANTAS, Fernando Antônio de Carvalho. Povos indígenas, conhecimentos tradicionais e recursos genéticos: a regulação jurídica da pesquisa "com" e "em" seres humanos. Revista de Direito Sanitário, São Paulo, v. 9, n. 3, p. 150-176, nov. 2008 /fev. 2009. Disponível em: http://www.revistas.usp.br/rdisan/article/view/13135/14940. Acesso em: 29 jun. 2020.

DELEUZE, Gilles. What is a dispositif? In: ARMSTRONG, Timothy J. et al. Michel Foucault philosopher. New York: Routledge, 1992. p. 159-168. Disponível em: https://nowherelab.dreamhosters.com/what\%20is\%20 dispositif.pdf. Acesso em: 23 out. 2020.

FERES, Marcos Vinício Chein; MOREIRA, João Vítor Freitas. Proteção jurídica da biodiversidade amazônica: o caso do conhecimento tradicional. Revista Direito Ambiental e Sociedade, Caixas do Sul, v. 4, n. 2, p. 9-36, 2014. Disponível em: http://www.ucs.br/etc/revistas/index.php/direitoambiental/article/viewArticle/3081. Acesso em: 29 jun. 2020.

FROTA, Hidemberg Alves da. Noções fundamentais sobre o dano existencial. Revista eletrônica [do] Tribunal Regional do Trabalho da $9^{a}$ Região, Curitiba, v. 2, n. 22, p. 62-78, set. 2013. Disponível em: https://juslaboris. tst.jus.br/handle/20.500.12178/95532. Acesso em: 28 jun. 2020.

GUIMARÃES, Verônica Maria Bezerra. A mitologia como elemento construtor de sustentabilidades. Veredas do Direito, Belo Horizonte, v.15, n.31, p.271-291, jan./abr. 2018. Disponível em: http://revista.domhelder.edu.br/ index.php/veredas/article/view/1192. Acesso em: 10 out. 2020.

HALL, Donald E. Subjectivity. New York: Routledge, 2004.

HENDRIX, Burke A. Ownership, authority, and self-determination. Philadelphia: The Pennsylvania State University Press, 2008.

JACOB, W. J.; CHENG, S. Y.; PORTER, M. K. Global review of indigenous education: issues of identity, culture, and language. In: JACOB, W. J.; CHENG, S. Y.; PORTER, M. K. (ed.). Indigenous Education. Dordrecht: Springer, 2015. p. 1-35. DOI: https://doi.org/10.1007/978-94-017-9355-1_1. Disponível em: https://link.springer. com/chapter/10.1007\%2F978-94-017-9355-1_1. Acesso em: 23 out. 2020.

KAHMANN, Andrea Cristiane et al. Línguas, livros e leis: o apagamento da cultura indígena e resistência. Veredas do Direito, Belo Horizonte, v. 17, n. 37, p. 61-87, jan./abr. 2020. Disponível em: http://revista. domhelder.edu.br/index.php/veredas/article/view/1703. Acesso em: 10 out. 2020.

REZENDE, Elcio Nacur; NASCIMENTO, Simone Murta Cardoso do. Princípios do desenvolvimento sustentável e da equidade intergeracional sob a ótica do conceito de "Outro" de Lacan. Revista Thesis Juris - RTJ, São Paulo, v. 7, n. 2, p. 344-364, jul./dez. 2018. Disponível em: https://periodicos.uninove.br/thesisjuris/article/ view/11274/5263. Acesso em: 25 nov. 2020.

SAMPAIO. José Adércio; REZENDE, Élcio Nacur. Meio ambiente: um direito fundamental de segunda categoria. Veredas do Direito, Belo Horizonte, v. 17, n. 38, p. 273-289, maio/ago. 2020. Disponível em: http://revista. domhelder.edu.br/index.php/veredas/article/view/1875 . Acesso em: 09 out. 2020.

SANTILLI, Juliana. Conhecimentos tradicionais associados à biodiversidade: elementos para a construção de um regime jurídico sui generis de proteção. In: PLATIAU, Ana Flávia Barros; VARELA, Marcelo Dias (coord.).

Diversidade biológica e conhecimentos tradicionais. Belo Horizonte: Del Rey Editora, 2004. p. 341-369. Disponível em: http://moodle.stoa.usp.br/file.php/1087/Aula_13_Juliana_Santilli_Conhecimento_tradicional_ associado_a_biodiversidade_elementos_para_a_const.pdf. Acesso em: 26 set. 2020.

SILVEIRA, Edson Damas. Direitos fundamentais indígenas, movimento socioambiental e a formatação do estado na modernidade. Veredas do Direito, Belo Horizonte, v. 6, n. 12, p. 25-56, jul./dez. 2009. Disponível em: http://revista.domhelder.edu.br/index.php/veredas/article/view/157. Acesso em: 10 out. 2020.

SIMPSON, Leanne. Indigenous environmental education for cultural survival. Canadian Journal of Environmental Education, North Bay, v. 7, n. 1, p. 13-25, 2002. Disponível em: https://cjee.lakeheadu.ca/issue/ view/34. Acesso em: 18 nov. 2020. 
SOARES, Flaviana Rampazzo. Do caminho percorrido pelo dano existencial para ser reconhecido como espécie autônoma do gênero "danos imateriais". Revista da AJURIS, Porto Alegre, v. 39, n. 127, p. 197-227, set. 2012. Disponível em: http://ajuris.kinghost.net/OJS2/index.php/REVAJURIS/article/view/765. Acesso em: 28 jun. 2020.

Recebido em: 12.11 .2020

Aceito em: 24.08.2021 